\title{
Immunotherapy of pediatric brain tumor patients should include an immunoprevention strategy: a medical hypothesis paper
}

\author{
Lara Driggers $\cdot$ Jian-Gang Zhang $\cdot$ \\ Elizabeth W. Newcomb $\cdot$ Lisheng Ge . \\ Neil Hoa $\cdot$ Martin R. Jadus
}

Received: 9 April 2009/Accepted: 21 September 2009/Published online: 4 October 2009

(C) The Author(s) 2009. This article is published with open access at Springerlink.com

\begin{abstract}
Adults diagnosed with Glioblastoma multiforme $(\mathrm{GBM})$ are frequently faced with a $7 \%$ chance of surviving 2 years compared with pediatric patients with GBM who have a $26 \%$ survival rate. Our recent screen of possible glioma-associated antigen precursor protein (TAPP) profiles displayed from different types of pediatric brain tumors showed that pediatric patients contained a subset of the tumor antigens displayed by adult GBM patients. Adult GBM possess at least 27 tumor antigens that can potentially stimulate $\mathrm{T}$ cell immune responses, suggesting that these tumors are quite antigenic. In contrast, pediatric brain tumors only expressed nine tumor antigens with mRNA levels that were equivalent to those displayed by adult GBM. These tumor-associated antigens could be used as possible targets of therapeutic immunization for
\end{abstract}

L. Driggers - J.-G. Zhang · L. Ge · N. Hoa - M. R. Jadus ( $($ ) Pathology and Laboratory Medicine Service, Molecular Medicine Health Care Group, VA Long Beach Healthcare System, Box 113, 5901 E. 7th Street, Long Beach, CA 90822, USA

e-mail: martin.jadus@va.gov

\section{J.-G. Zhang · M. R. Jadus}

Department of Pathology \& Diagnostic and Lab Medicine, University of California, Irvine, CA 92697, USA

E. W. Newcomb

New York University Cancer Center, New York, NY 10016, USA

E. W. Newcomb

Department of Pathology, New York University School of Medicine, 550 First Ave. MSB 128, New York, NY 10016, USA

M. R. Jadus

Neuro-Oncology Program, Chao Comprehensive Cancer Center, University of California, Irvine, Orange, CA 92868, USA pediatric brain cancer patients. Children have developing immune systems that peak at puberty. An immune response mounted by these pediatric patients might account for their extended life spans, even though the pediatric brain tumors express far fewer total tumor-associated antigens. Here we present a hypothesis that pediatric brain tumor patients might be the best patients to show that immunotherapy can be used to successfully treat established cancers. We speculate that immunotherapy should include a panel of tumor antigens that might prevent the out-growth of more malignant tumor cells and thereby prevent the brain tumor relapse. Thus, pediatric brain tumor patients might provide an opportunity to prove the concept of immunoprevention.

Keywords Tumor antigens - Immunotherapy · Glioblastoma multiforme · Fibrillary astrocytoma · Pilocytic astrocytoma $\cdot$ Ependymoma

\section{Background}

Glioblastoma multiforme (GBM) from adult patients look morphologically identical to those GBM derived from pediatric patients. The cell growth patterns, vascular supply and pathology including the central pallisading necrosis are indistinguishable from each other. Adult GBM patients (ages $>55$ ) have a 2 year survival less than $7 \%$ (without temozolomide), compared with $26 \%$ survival of pediatric GBM (without temozolomide) [1]. Since there is a difference in survival between the two GBM patient populations, the question remains whether these GBMs are two separate diseases arising from two different genetic defects that converge into the same pathology or just one disease that diverges due to selective pressures within the host. Figure 1 compares the differences in life expectancies among 

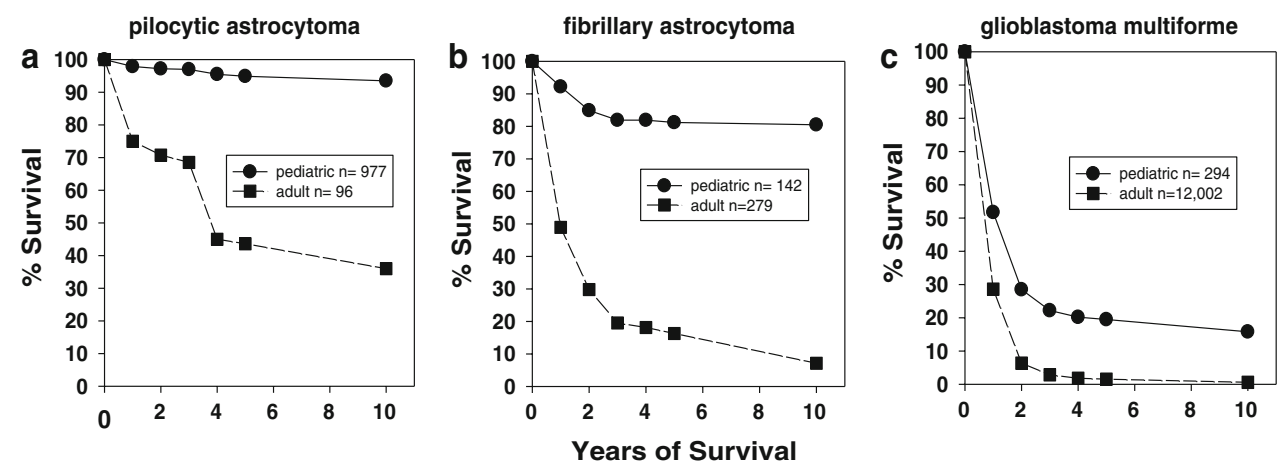

Fig. 1 Differences in survival between pediatric patients and adult patients diagnosed with the same brain cancers (pilocytic astrocytomas [panel a], protoplasmic \& fibrillary astrocytomas [panel b] and glioblastoma multiforme [panel c]). Data taken from SEER (19732004) is plotted for survival after 1, 2, 3, 4, 5 and 10 years after initial diagnosis. The pediatric patients included those from 0 to 19 years,

pilocytic astrocytoma [panel a], fibrillary astrocytoma [panel b] and GBM [panel c] patients by age; i.e., pediatric (0-19 years) and adult (45-74 years) patients. The 10 year survivals of pediatric patients with other subtypes of pediatric brain tumors are much longer compared with GBM. For low grade gliomas like fibrillary astrocytomas it is $81 \%$, while survival for pilocytic astrocytoma patients is 93\%. Overall, the survival of pediatric patients with these different types of brain cancers is better than those found in the corresponding adult patients as reported by Central Brain Tumor Registry (CBTR). Therefore some differences (either genetic and/or non-genetic) are responsible for these different outcomes. Further investigations as discussed here may allow advances to be applicable to the treatment of adults and children diagnosed with brain cancers.

Our recent Journal of Neuro-Oncology paper [2] examined the expression of 31 possible "glioma-associated" antigen precursor proteins (TAPP) by quantitative real time PCR (qRT-PCR) techniques from 37 human brain tumor patients. Our study included: 11 adult GBM (3 recurrent), 5 pediatric GBM (1 recurrent), 4 primary lowgrade fibrillary gliomas and 10 primary juvenile pilocytic astrocytomas. These "glioma-associated" antigens we used to generate TAPP profiles were selected based on prior studies by others, who showed human cytotoxic T lymphocyte (CTL) responses were induced by these antigenic peptides against a wide range of cancers from adults. In addition, these proteins are expressed or over-expressed by glioma cells. We initially speculated that the TAPP profiles of both the adult and pediatric GBM would be identical, since they are histopathologically indistinguishable from each other. We also postulated that the other tumor subtypes would have different TAPP profiles from pediatric patients, because they were morphologically different cancers. Unexpectedly, we saw that there were four while the adults were 45-74 years of age. The number of patients for each group is shown in the legend boxes. By ANCOVA analysis the pediatric pilocytic and fibrillary astrocytoma patient are significantly different, $P=0.002$ and $P=0.001$, respectively from the adults. For the GBM patients, the $P$ value is 0.373

different global TAPP profiles of tumor antigens among the adult GBM and the pediatric brain tumors.

In group 1, the adult GBM and the pediatric tumors expressed the same amount of mRNA for 9 antigens. In group 2, the adult GBM expressed more mRNA for 9 antigens compared with the pediatric brain tumors. For group 3, only the adult GBM expressed mRNAs for 9 different antigens, while in group 4 , there was no consistent expression of mRNA for 4 of the tumor antigens. The antigen profile of the adult GBM was unexpectedly different from the pediatric GBM. The pediatric GBM TAPP expression profile was a smaller subset of the antigens displayed by the adult GBM. Additionally, most of the other pediatric brain tumors (low grade fibrillary astrocytomas, pilocytic astrocytomas and ependymomas) had TAPP profiles that were more similar to each other and to pediatric GBM than they were different from each other. Table 1 (reproduced with permission) lists the TAPP antigenic profiles of the various tumors from our studies.

One empirical observation was that the adult GBM expressed many more tumor antigens (total of 27 out of 31 antigens), compared with the pediatric brain tumors which all presented fewer tumor antigens (ranges of 8-17 antigens/tumor type). One limitation to our study was that we only examined mRNA and not the protein and/or the peptides needed for MHC binding. In our prior study using GBM cell lines where we examined 16 tumor antigens [3], the amount of the mRNA levels correlated very well with the protein as detected by immunostaining and intracellular flow cytometry; i.e.; high mRNA levels showed high protein expression and cells that had little or no mRNA had little or no protein expression, respectively. So if our study with freshly isolated surgical specimens can be extrapolated to the protein/peptide level, we conclude that adult GBM would actually be "more antigenic" to $T$ cells than 
Table 1 Potential targeted antigens for immunotherapy of human brain cancers

\begin{tabular}{ll}
\hline Tumor type & Antigens \\
\hline Adult GBM & Aim-2, Art-1*, Art-4, B-cyclin, EphA2*, Ezh2, Fos11*, Galt-3, GnT-V*, Her2/Neu, HNRPL*, \\
& IL13R $2^{*}$, Mage-1, MRP-3*, PTH-rP, Sart-1*, Sart-2, Sart-3, Sox 11* Survivin, hTert, Trp-1, \\
& Trp-2* Tyrosinase, Ube2V* Whsc2, YKL-40* \\
Pediatric GBM & Art-1* EphA2*, Fos11*, HNRPL*, MRP-3, Sox 11*, Trp-2*, Ube2V*, YKL-40* \\
Low grade fibrillary astrocytomas & Art-1*, B-cyclin, EphA2*, Ezh2, Fos11*, GnT-V*, Her2/Neu, HNRPL*, IL13R $22^{*}$, \\
& MRP-3, Sart-1*, Sart-3, Sox 11*, Trp-2*, Ube2V*, Whsc2, YKL-40* \\
Juvenile pilocytic astrocytomas & Art-1*, EphA2*, Ezh2, Fos11*, HNRPL*, MRP-3*, Sart-2, Sox 11*, Ube2V*, Whsc2, YKL-40* \\
Ependymomas & Ezh2, Fos11*, Her2/Neu, HNRPL*, Sox 11*, Trp-2*, Ube2V*, YKL-40*
\end{tabular}

Asterisks indicate that the amount of mRNA was statistically equivalent

the corresponding pediatric GBM. This conclusion appears paradoxical given the survival data shown in Fig. 1c. These results raises the simple question: why doesn't the increased antigenicity of adult GBM lead to increased immunogenicity, correlated perhaps with increased survival?

Another caveat that must be noted is that the tumorassociated antigens we have examined are those defined largely from adults with GBM, which could potentially skew our proposed analysis. If pediatric GBM come from a different set of genetic defects [4], then pediatric GBM may have pediatric GBM-restricted TAPP, that are not seen within the adult GBM. Hence pediatric brain cancer researchers should be cognizant of this possibility. But this offers possible fertile grounds to find new pediatric brain tumor-specific antigens.

\section{Adult GBM have more defensive mechanisms}

As described above, one TAPP expression profile of 9 antigens was either expressed more in adult GBM compared with pediatric GBM (group 2) or exclusively expressed in adult GBM compared with pediatric GBM (group 3). We will focus on 3 of these tumor antigens: Multi-drug resistance protein-3 (MRP-3), human Telomerase reverse transcriptase (hTert), and Survivin (Fig. 2). These 3 tumor antigens may provide some insight into why pediatric GBM may be easier to treat and why the pediatric GBM patients survive longer than adult GBM patients. Expression of these 3 genes correlates with a poorer prognosis in many different cancer types [5-8], suggesting these genes participate in tumor progression. Studies have shown that CTLs are capable of killing cancer cells expressing these 3 epitopes [9-12]. Hence these adult GBM should still be susceptible to this $\mathrm{T}$ cell-mediated cytotoxicity.

MRP-3 is a reverse drug transporter that expels chemotherapeutic drugs out of the tumor cells, making these cells resistant to the actions of various cytotoxic compounds. All 5 of the pediatric GBM samples displayed lowered amounts of mRNA for this gene, compared with the adult GBM. The one sample that had the highest MRP3 mRNA came from a primary GBM patient. Overall, this difference in MRP-3 expression may help explain why most pediatric GBM are probably more susceptible to chemotherapy compared with adult GBM.
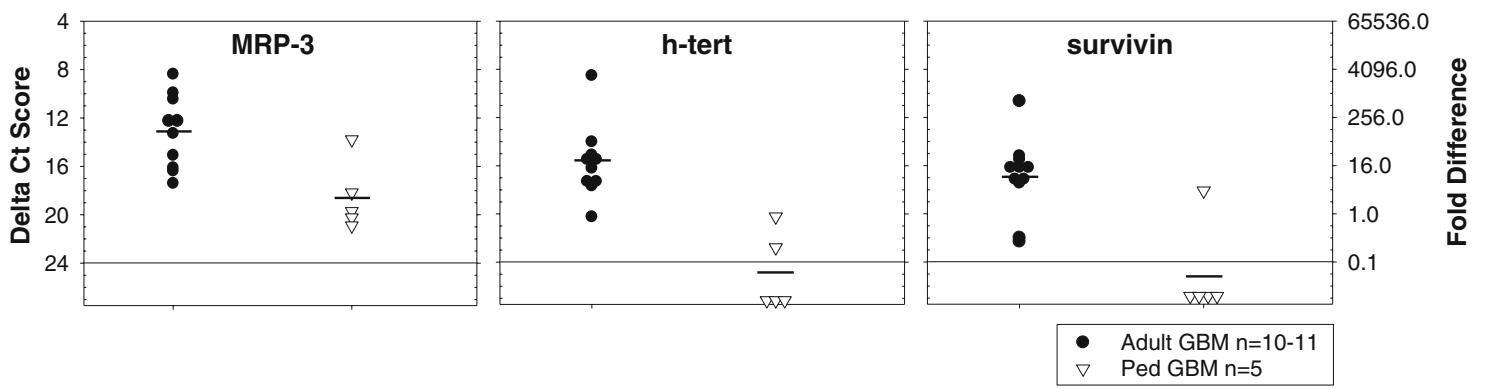

Fig. 2 Differences between adult-derived and pediatric-derived for 3 TAPP genes. The amount of mRNA was quantitated by a $\Delta C_{t}$ value on left $y$-axis in comparison to the 18S RNA. The $\Delta \mathrm{C}_{\mathrm{t}}$ value of 20 was given an arbitrary value of 1 and the fold-difference is presented on right $y$-axis. The expression of MRP-3, hTert and survivin are shown within their respective boxes. Pediatric GBM patient 847 had the highest expressing mRNA in the MRP-3 cohort, Pediatric GBM patient 1292 displayed the most survivin mRNA and the second most hTert mRNA. Pediatric GBM patient 1476 was the recurrent GBM and had the most hTert mRNA. The legend box indicates the number of tumors that were analyzed. By a student's $t$ test, all values between the pediatric and adult GBM were statistically significant $(P<0.05)$ 
hTert is the enzyme that stops the teleromeres from shortening after each round of DNA replication. This polymerase therefore prevents the tumor cells from going into senescence and/or dying of apoptosis after the chromosomal teleromers reach their lower limits. Many low-grade brain cancers can not be developed into established cell lines because the tumor derived cells eventually become senescent. This lack of hTert may help explain the inability to propagate these lower grade glioma cell lines. Two pediatric GBM samples showed low levels of hTert expression, which we believe could be biologically relevant. The specimen from the recurrent pediatric GBM had the highest hTert mRNA expression within the pediatric GBM cohort. This finding is important since tumor selection for rapidly hTert+ growing clones could be occurring, which ultimately allows the tumor cells to continue to proliferate preventing the tumor cells from becoming senescent.

Survivin is an anti-apoptotic protein that functions on several levels to make cells more resistant to apoptosisinducing pathways at either the nuclear or the cytoplasmic levels. One pediatric patient with a primary GBM showed expression of survivin mRNA that was equivalent to that found in the adult GBM. Interestingly, this same patient also showed some detectable level of hTert mRNA as well.

Three of the 5 pediatric GBM expressed low levels of these protective molecules that could represent defense mechanisms for the tumor cell, whereby the resistant cells can be positively selected via drugs, radiation, or biological therapies. The lack of a defense in pediatric GBM might be the Achilles' heel by which these brain tumors could be successfully attacked by a properly activated immune system.

Adult GBM, in addition to MRP-3, hTert and survivin, have other defensive molecules in the following categories: (1) anti-apoptotic genes like Bcl-2, Bcl-w, Mcl-1 [13], inhibitor of apoptosis (IAPs) proteins [14]; (2) immunosuppressive agents like transforming growth factor- $\beta$ [15], interleukin-10 [16], prostaglandin via cyclo-oxygenase 2 [17]; (3) immune response; Treg involvement [18, 19], decreased HLA expression, which prevent immune recognition [20]; (4) other mechanisms reviewed in [21, 22]. These additional tumor defensive strategies by adult GBM may account for the inability to generate/sustain lasting immune responses in spite of increased antigenicity. The role of these protective factors within pediatric brain tumors is presently unknown and deserves future investigations.

\section{Clinical success of treating pediatric brain tumor patients comes at a price}

Successful clinical interventions of pediatric patients by chemo and radiation therapies do come at a price that is not immediately obvious by the survival statistics shown in Fig. 1. Pathological changes in treated brain tissues take months to years to develop and include white and gray matter abnormalities, microvascular occlusions, calcifications and demyelination [reviewed in 23, 24]. These physiological changes translate into behavioral and developmental issues, such as loss of IQ [25]. Some studies report that $40-100 \%$ of their patients have neurocognitive problems [23], perceptual skill defects, learning disabilities which ultimately results in academic failure. Long term survivors later develop serious social/psychological problems that prevent them from becoming productive members of society. These patients often can't maintain steady jobs, develop drug dependence, and have general psychological distress, along with failed marriages. These cognitive and behavioral health issues could be due to the toxic effects of drugs and radiation upon the developing neuronal and supporting stromal cell networks. These sequela are less visible in adults, because their overall survival is shorter. Thus, there is a dire need for therapies that improve the quality of life issue of pediatric patients and immunotherapy may be one avenue to accomplish this goal.

\section{Current status of immunotherapy for brain tumors}

There is some circumstantial evidence that the immune system plays a role in the patient's survival with brain cancer. Atopic patients (13 out of 115 patients with elevated $\operatorname{IgE}$ levels, $P<0.0007)$ in the San Francisco area had a lowered risk of developing glioma [26]. Additionally; those glioma patients with elevated IgE levels survived 9 months longer [26]. This atopic relationship was confirmed in a meta-analysis compiled from eight independent studies using 3,450 glioma patients [27]. Interleukin-4 (IL4), made by $\mathrm{T}$ helper type 2 cells, is commonly associated with the production of IgE by B cells. IL-4 gene therapy in rats also produced enhanced glioma survival [28, 29]. It was assumed that this increased survival was due to the actions of immunized T cells, but other explanations could be possible. Recently it was shown that interleukin-4 and granulocyte-macrophage colony stimulating factor activated human dendritic cells (DC) could directly kill several human glioma cells in vitro [30]. Machulla et al. [31] and Tang et al. [32] showed statistical associations of GBM incidence with certain HLA phenotypes. Tang et al. [32] studied 155 GBM patients and concluded those patients, who possessed the HLA-B55 antigen died significantly quicker (relative risk: $2.27 ; P<0.01$ ) than non-HLA-B55 patients. In contrast, those HLA-A $32+$ GBM patients survived significantly longer (relative risk: $0.45 ; P<0.01$ ). The identification of these various mechanisms of antiglioma activities need further investigation and may 
provide additional insight that could be fully exploited by clinicians.

Cell-based immunotherapy has been viewed as a bright hope to treat many types of cancers. The theoretical advantage of these immune effectors is that they can migrate throughout the body and actively seek out and destroy the tumor cells. These effector lymphocytes should remain present until the cancer is eliminated and then memory $\mathrm{T}$ cells could be generated. Over the years, several techniques have produced a few long-term successes [3341]. Effector lymphocytes like CTLs, lymphokine activated killer (LAK) cells, mitogen activated killer cells and mixed lymphocyte reactive cells have been effective in killing gliomas in vitro. Success has only occurred sporadically in a few GBM patients after being treated with these activated lymphocytes. These sporadic successes nevertheless have further spurred clinical research.

Dranoff et al.'s study [42] with murine melanomas was instrumental in showing that more effective and durable immune responses were generated by activating the host's dendritic cells, first, rather than just stimulating effector $\mathrm{T}$ cells. This study showed that immunization with B16 melanoma cells transduced with granulocyte-macrophage colony stimulating factor (GM-CSF) and IL-4, but not with interleukin-2 (IL-2) or tumor necrosis factor (TNF) transduced cells, produced lasting immunity. They attributed this response to the host's dendritic cells functioning as antigen presenting cells (APC), which stimulated the host's effector lymphocytes. Additionally, better memory T cells are thought to be produced via this dendritic cell's APC function. Recent studies from Europe [43], UCLA [44] and Cedar-Sinai [45] have shown that the mean time to progression for adult GBM patients increased in some responder populations by vaccination with the patient's dendritic cells pulsed with autologous tumor homogenates. One key finding that has been repeatedly reported is that this immunotherapy is relatively safe with few serious side effects. Most likely, this dendritic cell-based immunotherapy will be used as an adjunct therapy after chemo- and radiation therapies are administered, as opposed to a standalone therapy. There have been some studies that show that immunotherapy can enhance chemotherapy towards glioma cells [46, 47]. Even then immunotherapy might still have to be combined with other biological-based approaches such as anti-angiogenesis to further improve immunotherapeutic efficacy [48].

\section{Immunotherapy with or without autoimmunity?}

Immunotherapy has had some clinical success against some cancers when there are signs of autoimmunity occurring. In melanoma, autoimmune responses against non-tumorous melanocytes occur in a condition called vitiligo. Cellular-based vaccines [49], interferon-alpha $2 \beta$ [50] -based therapies, and anti-CTLA-4 antibody therapies, (which target self-T cell regulatory pathways), demonstrate improved anti-cancer immune responses when simultaneously seeing some autoimmunity [51]. In bone marrow transplantation (BMT) for hematological malignancies, a similar debate occurred years ago. Here if some histoincompatibility between host and donor was included in the BMT, a condition called graft-versus-leukemia occurred; this was associated with better leukemia remissions [52, 53]. However, the fine line cannot be crossed where lifethreatening graft-versus-host disease occurs. In most clinical settings against brain cancers, little autoimmunity has occurred as a result of whole cell vaccines. However, temporary side effects do result in fever, skin rashes, and myalgias, but these dissipate over the next few days, without lasting effects. The results of these empirical observations have lead to the debate whether one wants to encourage autoimmune responses, as they may lead to tumor cell destruction. In adult GBM use of mixed lymphocyte reactive (MLR) activated lymphocytes has the potential to produce long-term survivals [37, 38]. One of the concerns of this study was that autoimmunity could occur, but empirical results have shown the concern was unwarranted.

\section{Immunotherapy of pediatric brain tumor patients}

Although pediatric tumors express fewer known tumor antigens compared with adult GBM, they do express about nine tumor antigens (Art-1, EphA2, Fosl1, GnT-V, HNRPL, Sox11, Ube2V, and YKL-40). These antigens could be considered excellent possible immuno-targets. Vaccination with dendritic cells pulsed with tumor lysates or synthetic peptides that the patients' tumors possess are the best current approaches for immunotherapy.

The advantages to these patients are two-fold. First, pediatric patients especially those around puberty should possess the best immune responses in their lifetime. So tumor antigen vaccination should boost an already strong immune system. Studies show that young individuals make stronger antibody titers and that less antigen is needed to maximally stimulate their $\mathrm{T}$ cell responses [54, 55]. In additional, the innate immune system is also diminished in the elderly [56]. Immunotherapy of pediatric brain tumor patients is already is considered safe with relatively few side effects [57] and some increased survival have already been reported [58].

Immunotherapy has several advantages for pediatric patients. First, it could prevent the physiological and psychological problems that radiation and chemotherapy 
cause, by perhaps reducing the amounts of radiation or chemotherapy that are needed. Second, the predicted life spans of these pediatric patients, especially with low grade fibrillary/protoplasmic astrocytomas and pilocytic astrocytomas are given in years. Thus, there is ample time for the immune system to work. Therefore, one could consider this longer period of time, an ideal opportunity to do prophylactic vaccination. Here the tumors are still relatively small, slow growing but still susceptible to immune-mediated killing. This type of tumor burden also matches the ability of various immunotherapies to control small, slower growing tumors. Since pediatric GBM have fewer defense mechanisms, these cancer cells should be controlled easier by a fully activated and mobilized immune system.

\section{Immune systems of young versus older people}

Younger individuals have robust immune systems. Immunity peaks around puberty, so these experimental successes could be partly due to the vitality of the younger immune systems. The majority of oncology patients, especially GBM, are well past puberty, when their cancers appear. By age 50, the human thymus has atrophied, so no new $\mathrm{T}$ cells are produced. Those $\mathrm{T}$ cells that are still around may be approaching replicative senescence, since they have already divided many times and their teleromeres have significantly shortened. So these "exhausted" T cells coming from older people don't have the expansive vitality as those cells coming from teenagers. In contrast, younger individuals' thymus is still capable of generating $\mathrm{T}$ cell diversity, which may specifically adapt to the brain tumor-associated antigens. Similar conclusions have been recently been reviewed by Jacobs and colleagues [59].

One direct application of this concept for adults with GBM may include a strategy, where the immune cells from a patient's offspring are used for therapy in their parents. Since the patient's natural offspring share 1 HLA haplotype with themselves, the children's DC and T cells could be stimulated in vitro with the parent's tumor. Better yet, the grandchildren, if HLA matched could be used as a source of the activated lymphocytes. These ex vivo stimulated $\mathrm{T}$ cells could then be infused back into their parent or grandparent with the glioma. These activated immunocytes may then provide a more vigorous immune response than the adult's immunosenscent lymphocytes.

\section{The concept of immunoprevention}

Several years ago, Forni et al. [60], reviewed the problems of human immunotherapy with end-stage cancer patients. They suggested that the best use of immunotherapy might be in controlling minimal residual disease, where there are few cancer cells. They also proposed a concept called immunoprevention. This is a very reasonable strategy for those people who might be prone to develop cancer either due to family genetics or due to the exposure of infectious agents (HBV, HCV, HPV, H. pylori, etc.). Thus, this immunopreventive strategy can stop a limited number of cancers, i.e., hepatocellular carcinoma, cervical, stomach cancer, etc. before they get firmly established. The other critical issue here, is that the immune system is provided ample time, so it can control these very small developing cancers or pre-cancers. Many of these transformed cells are also relatively slower growing tumors, when compared to relapsing tumors. Most cancer patients don't completely respond well to immunotherapy because their tumors are just too mutationally diverse, too big, and too fast growing. Also not sufficient time is given to the immune system to eliminate the tumor. If the immune system can eliminate more cancer cells than the tumor cells can replicate, then the cancer regresses. Thus, immunoprevention does have a strong appeal and should be used whenever possible.

\section{Immunotherapy may prevent the development of secondary gliomas}

One practical benefit of immunotherapy for the treatment of low grade gliomas is that it could prevent the risk of developing secondary GBM. These secondary Stage IV GBM evolve from prior low grade gliomas: pilocytic astrocytomas (stage I), diffuse astrocytomas (stage II) or anaplastic astrocytomas (stage III). Secondary gliomas occur about $5-10 \%$ of the time. So if preventing secondary GBM is desired, one could use all the antigens that GBM possess (Table 1) and stimulate multiple $\mathrm{T}$ cell clones that could prevent the progression to secondary GBM. However, the duration of the vaccination schedule and how long it is effective against secondary GBM, all remain to be elucidated. Recently, a report has described that metformin (a drug used for diabetes management) can enhance CTL memory cells [61]. So this drug may be very useful in improving immunotherapy.

\section{What tumor antigens should be targeted in pediatric brain tumors?}

What tumor antigens should be used to treat pediatric brain tumor patients? Obviously, those antigens that the tumor is making are the logical choice. Those vaccination programs using autologous tumor are the best option for encompassing the entire tumor antigen spectrum. 
But what happens if those autologous tumor antigenic proteins are not sufficiently high in protein concentration to induce immune responses, or not enough of the resected tumor specimen is available for dendritic cell loading? Synthetic peptides can be used to pulse the dendritic cells prior to their induced maturation. But this requires that the patient be HLA typed before therapy to insure that the proper MHC binding sites are available. Most glioma tumor antigens currently known are restricted for either HLA-A2 or HLA-A24 (this just probably reflects a bias in that most researchers just used HLA-A2 or HLA-A24 positive cancer cells). Using the entire TAPP fed to the dendritic cells could also accomplish this same goal. This strategy allows the DC to process all the peptides, so that multiple antigenic determinants can be expressed on the different MHC class I or class II alleles that each DC expresses, allowing multiple $\mathrm{T}$ cell clones to get activated. Best of all, perhaps other immunogenic peptides are being generated that could enhance these anti-tumor immune responses, via a process called epitope spreading [62]. Here an immune response towards one immunodominant epitope could stimulate other $\mathrm{T}$ cell clones that are recognizing different determinants of the same antigen precursor protein.

Many regulatory agencies and IRBs truly want to advance the medical science by doing well-founded systemic studies, where only a few antigens are tested to assess vaccinating efficacy; i.e. tetramer analysis, ELISPOT, intracellular cytokine content, etc. This precludes a shot-gun approach (via tumor homogenates), so that if successes are found, it is nearly impossible to pinpoint which antigens proved to be the key one(s). The danger here with these very refined studies where only a few antigens are investigated, is that selection could produce antigen negative variant cells. A current example of GBM selection is the epidermal growth factor receptor variant III (EGFRvIII) positive cells. After vaccination with dendritic cells loaded with the EGFRvIII peptide, the EGFRvIII+ cells were effectively removed, while selecting EGFRvIII negative clones [63].

In our study of TAPP profiles, we saw that some pediatric patient's GBM cells expressed low amounts of these apoptosis-resistance genes, MRP-3, hTert and survivin. Fortunately, tumor cells expressing these 3 antigens were shown not to be resistant to $\mathrm{T}$ cell-mediated killing. We believe it makes sense to include these tumor antigens in immunotherapy trials, regardless of whether the patients' current tumor possess these antigens. This proposed therapy eliminates those cancer clones before they are fully selected and before they can accumulate more defensive proteins. Activated anti-MRP-3 and anti-hTert specific T cells should eliminate these MRP-3 and hTert positive cancer cells, thereby preventing the remaining cells from being positively selected. This strategy might allow the tumor to be more sensitive to classical chemotherapeutics, thereby potentially reducing drug dosage and minimizing the eventual side-effects. The proof of principal of this concept occurred using the TRAMP mouse prostate cancer model. Here prophylactic vaccination against mTert delayed the tumor incidence in animal's pre-disposed prostate cancers [64].

Other tumor antigens that could be possible targets of immunotherapy are CD133 and ATP-Binding Cassette, subfamily G member-2 (ABCG2). Both of these markers of "stem cell"-like genes. Both molecules function as reverse chemotherapeutic drug transporters [65]. CD133+ cells are both radioresistant [66] and chemo-resistant [67], suggesting these cells play a major role in being impervious to various standard therapies. A high content of CD133+ cells within GBM has been reported to be associated with a worse prognosis [68]. Maternal embryonic leucine zipper kinase (MELK) is another tumor antigen that encodes for a kinase, which is found in "glioma stem-like" cells [69]; MELK can stimulate CTLs [70]. Thus, "cancer stem cells" offer multiple targets for immunotherapy. By killing these relatively scarce "stem cells" it should be easier to eliminate these tumor forming cells.

In conclusion, the best antigens to use for pediatric brain tumors are those antigens that the current tumor is expressing. Vaccination with these potential antigens, MRP-3, hTert and survivin, may also prevent tumor escape variants from being selected while "buying" the patient more time. Immunization targeting stem cell antigens should be included in the vaccine cocktail, since this could eliminate the more potent cancer initiating cells. Thus, a global vaccination strategy should cut potential tumor growth on multiple different levels.

\section{The feasibility of clinical trials}

To conduct successful immunotherapy in children it will be important to choose the right patient populations to show clinical efficacy, before immunotherapy will make it to "mainstream medicine". Figure 3 summarizes the 10 year survival of four pediatric brain tumor patient populations, pilocytic astrocytomas, fibrillary/protoplastic astrocytomas, ependymomas and GBM. These populations show a wide spectrum of survival rates that can be theoretically explored. Each population has its own positives and negatives that need to be considered, before embarking on immunotherapy.

Pediatric GBM as with adult GBM have a very poor prognosis. Most of the mortality occurs within the first 2 years, but then it levels off to a $20 \%$ survival for the next 8 years. If therapeutic vaccination has any effect in this 


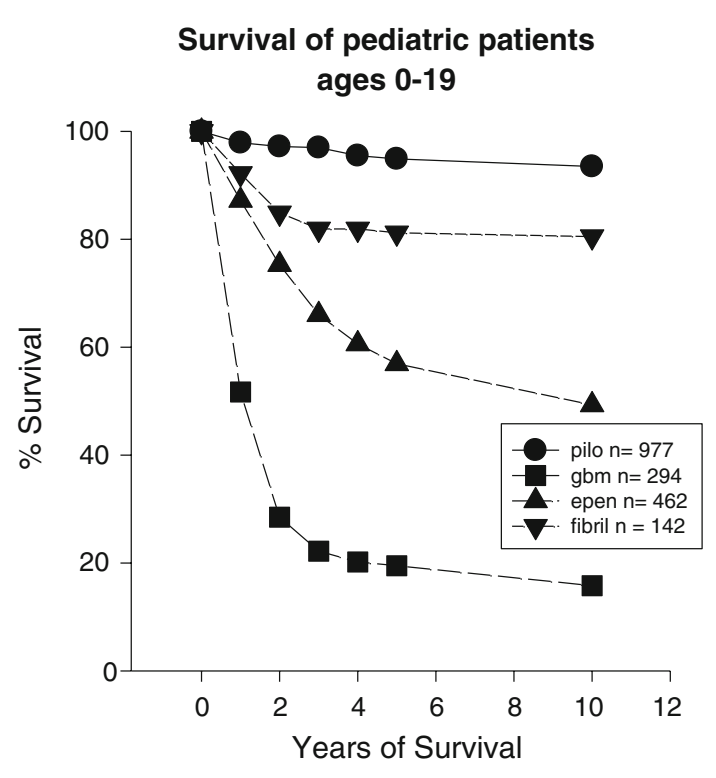

Fig. 3 Comparison of 10 year survival for four different types of pediatric tumors. SEER data from 1973 to 2004 is plotted for 10 year survival for patients aged from 0 to 19 years of age

population, it would be observed within the first 2 years. The limitation of using this patient population is similar to that with adult GBM, in that tumor growth may be too fast to be controlled by the immune system, unless the immune response is incredibly potent.

Pediatric ependymomas have a better survival than pediatric GBM. After 10 years survival is $50 \%$. The death rate is slower than GBM. One limiting factor with these children is that the greatest incidence of ependymomas occurs within children from birth to 4 years. Even though children's immune systems are developing, really young children probably don't have sufficient immunity or stamina that can be fully mobilized against a cancer. Functional DC can be generated from pediatric cancer patients of 1 year of age [71], but the yield of these DC from 3 to 4 year old patients can sometimes only yield 1-10 million DC/vaccination [72]. These numbers of DC might be suboptimal for the desired therapeutic responses. So if therapy is attempted with pediatric ependymomas, it should be done in bigger children who should be able to generate the necessary multiple millions of DC needed for reinfusion.

Fibrillary astrocytomas and pilocytic astrocytomas patients have good survival rates: $>80 \%$ for fibrillary and $>90 \%$ for pilocytic astrocytomas. Thus, there is plenty of time for the immunized lymphocytes to search out and destroy these tumor cells. Fibrillary/protoplasmic astrocytomas are unfortunately rare; only 142 are reported over the last SEER report. To prove a statistical benefit would require a long time to accrue sufficient numbers of patients. So these tumors are probably not the ideal population to study. Pilocytic astrocytomas are more common, with close to a thousand described over the same time span. But the major problem here is that their survival is greater than $90 \%$ for 10 years. So these proposed studies would require many more patients be enrolled and extended survival times would need to be examined to show some statistical advantage. So these proposed studies would require very long follow-up studies and very dedicated clinical researchers.

\section{Conclusions}

Patients diagnosed with brain cancers have a very unfavorable prognosis. A few patients do survive after various therapies, so there is hope that brain tumors can be cured. Pediatric patients survive much longer than adults afflicted with the same pathologies. Immunity generally peaks at puberty, so this may help explain why pediatric brain tumor patients might survive longer. Young people have more robust immune systems that might naturally enhance their therapeutic interventions. We showed that pediatric brain tumors express fewer tumor antigens when compared to the adult GBM. Even though the total number of tumor antigens is lower, those antigens could be the ones that their immune systems are responding to and could be attractive candidates for future immunotherapy. GBM derived from adults appear very antigenic. But adult GBM possess more defensive type molecules which make them resistant to various therapeutic interventions. Since pediatric tumors display lower levels of these "defense" type antigens, these tumor-associated antigens make attractive targets for immunopreventive interventions to prevent more malignant clones from developing. We believe that immunotherapy/immunoprevention may have its best success as an adjunct therapy against pediatric brain tumors, and could perhaps lower the dose and duration of radiation or chemotherapy required to cure these younger patients. This concept is actually modeled in most experimental animal systems which use young mice and rats. However, one thing is certain, these studies will be relatively challenging to conduct, since extended times are going to needed to show whether significant changes in survival has occurred in response to vaccination.

Acknowledgements We thank Drs. Paul Walker (University of Geneva) and Ronald Kim (University of California, Irvine) for many discussions over the years about various aspects of glioma immunology and pathology. We thank Drs. Sharon Gardner (New York University) and Daniela Bota (University of California, Irvine) for their clinical insights of pediatric brain tumors, as well as Drs. Hideho Okada, Carol Kruse, Andrew Cornforth and Chris Wheeler for discussions about their clinical trials and possible autoimmune responses. We also wish to express our appreciation to Dr. Mehrtash Hashemzadeh, for doing the hypothetical statistical analyses presented above to perform clinical trials. Supported by: This study was 
funded in part from grants obtained from the Veterans Affairs (MRJ); the Avon Breast Cancer Foundation via the University of California at Irvine Cancer Research Program (MRJ).

Open Access This article is distributed under the terms of the Creative Commons Attribution Noncommercial License which permits any noncommercial use, distribution, and reproduction in any medium, provided the original author(s) and source are credited.

\section{References}

1. CBTRUS (2005) Statistical report: primary brain tumors in the United States, 2007. In: Central Brain Tumor Registry of the United States. CBTRUS, Chicago, IL, USA

2. Zhang JG, Kruse CA, Driggers L, Hoa N, Wisoff J, Allen JC, Zagzag D, Newcomb EW, Jadus MR (2008) Tumor antigen precursor protein profiles of adult and pediatric brain tumors identifies potential targets for immunotherapy. J Neuro-Oncol 88:65-76

3. Zhang JG, Eguchi J, Kruse CA, Gomez GG, Fakhrai H, Schroter S, Ma W, Hoa N, Minev B, Delgado C, Wepsic HT, Okada H, Jadus MR (2007) Antigenic profiling of glioma cells to generate antigenic vaccines or dendritic cell-based therapeutics. Clin Cancer Res 13:566-575

4. Suri V, Das P, Jain A, Sharma MC, Borkar SA, Suri A, Gupta D, Sarkar C (2009) Pediatric glioblastomas: a histopathological and molecular genetic study. Neuro Oncol 11:274-280

5. Tabori U, Ma J, Carter M, Zielenska M, Rutka J, Bouffet E, Bartels U, Malkin D, Hawkins C (2006) Human telomere reverse transcriptase expression predicts progression and survival in pediatric intracranial ependymoma. J Clin Oncol 24:1522-1528

6. Chakravarti A, Zhai GG, Zhang M, Zhang M, Malhotra R, Latham DE, Delaney MA, Robe P, Nestler U, Song Q, Loeffler J (2004) Survivin enhances radiation resistance in primary human glioblastoma cells via caspase-independent mechanisms. Oncogene 23:7494-7506

7. Steinbach D, Wittig S, Cario G, Viehmann S, Mueller A, Gruhn B, Haefer R, Zintl F, Sauerbrey A (2003) The multidrug resistance-associated protein 3 (MRP3) is associated with a poor outcome in childhood ALL and may account for the worse prognosis in male patients and T-cell immunophenotype. Blood 102:4493-4498

8. Calatozzolo C, Gelati M, Ciusani E, Sciacca L, Pollo B, Cajola L, Marras C, Silvani A, Vitellaro-Zuccarello L, Croci D, Boiard A, Salmaggi A (2005) Expression of drug resistance proteins Pgp, MRP1, MRP3, MRP5 and GST-pi in human glioma. J NeuroOncol 74:113-121

9. Yamada A, Kawano K, Koga M, Matsumoto T, Itoh K (2001) Multi-drug resistance-associated protein 3 is a tumor rejection antigen recognized by HLA-A2402-restricted cytotoxic T lymphocytes. Cancer Res 61:6459-6466

10. Domchek SM, Recio A, Mick R, Clark CE, Carpenter EL, Fox KR, DeMichele A, Schuchter LM, Leibowitz MS, Wexler MH, Vance BA, Beatty GL, Veloso E, Feldman MD, Vonderheide RH (2007) Telomerase-specific T-cell immunity in breast cancer: effect of vaccination on tumor immunosurveillance. Cancer Res 67:10546-10555

11. Fukuda S, Pelus LM (2006) Survivin, a cancer target with an emerging role in normal adult tissues. Mol Cancer Ther 5:10871098

12. Schmidt SM, Schag K, Muller MR, Weck MM, Appel S, Kanz L, Grünebach F, Brossart P (2003) Survivin is a shared tumorassociated antigen expressed in a broad variety of malignancies and recognized by specific cytotoxic $\mathrm{T}$ cells. Blood 102: 571-576

13. Strik H, Deininger DM, Streffer J, Grote E, Wickboldt J, Dichgans J, Weller M, Meyermann R (1999) BCL-2 family protein expression in initial and recurrent glioblastomas: modulation by radiochemotherapy. J Neurol Neurosurg Psychiatry 67:763-768

14. Ziegler DS, Wright RD, Kesari S, Lemieux ME, Tran MA, Jain M, Zawel L, Kung AL (2008) Resistance of human glioblastoma multiforme cells to growth factor inhibitors is overcome by blockade of inhibitor of apoptosis proteins. J Clin Invest 118:3109-3122

15. Constam DB, Philipp J, Malipiero UV, ten Dijke P, Schachner M, Fontana A (1992) Differential expression of transforming growth factor-beta 1, -beta 2 , and -beta 3 by glioblastoma cells, astrocytes, and microglia. J Immunol 148:1404-1410

16. Nitta T, Hishii M, Sato K, Okumura K (1994) Selective expression of interleukin 10 gene within glioblastoma multiforme. Brain Res 649:122-128

17. Prayson RA, Castilla EA, Vogelbaum MA, Barnett GH (2002) Cyclooxygenase-2 (COX-2) expression by immunohistochemistry in glioblastoma multiforme. Annals Diag Path 6:148-153

18. Fecci PE, Mitchell DA, Whitesides JF, Xie W, Friedman AH, Archer GE, Herndon JE II, Bigner DD, Dranoff G, Sampson JH (2006) Increased regulatory T-cell fraction amidst a diminished CD4 compartment explains cellular immune defects in patients with malignant glioma. Cancer Res 66:3294-3302

19. Heimberger AB, Abou-Ghazal M, Reina-Ortiz C (2008) Incidence and prognostic impact of FoxP3+ regulatory $\mathrm{T}$ cells in human gliomas. Clin Cancer Res 14:5166-5172

20. Walker PR, Dietrich PY (2001) Immune escape of gliomas. Prog Brain Res 132:695-698

21. Walker PR, Calzascia T, Dietrich PY (2002) All in the head: obstacles for immune rejection of brain tumors. Immunology 107:28-38

22. Yang MY, Zetler PM, Prins RM, Khan-Farooqi H, Liau LM (2006) Immunotherapy for patients with malignant glioma: from theoretical principles to clinical applications. Exp Rev Neurother 6:1481-1494

23. Mulhern RK, Palmer SL (2003) Neurocognitive late effects in pediatric cancer. Curr Probl Cancer 27:177-197

24. Tsuruda JS, Kortman KE, Bradley WG, Wheeler DC, Van Dalsem W, Bradley TP (1987) Radiation effects on cerebral white matter: MR evaluation. Am J Roentgenol 149:165-171

25. Glauser TA, Packer RJ (1991) Cognitive deficits in long-term survivors of childhood brain tumors. Childs Nervous Syst 7:2-12

26. Wrensch M, Wiencke JK, Wiemels J, Miike R, Patoka J, Moghadassi M, McMillan A, Kelsey KT, Aldape K, Lamborn KR, Parsa AT, Sison JD, Prados MD (2006) Serum IgE, tumor epidermal growth factor receptor expression, and inherited polymorphorisms associated with glioma survival. Cancer Res 66:4531-4541

27. Linos E, Raine T, Alonso A, Michaud D (2007) Atopy and risk of brain tumors: a meta-analysis. J Natl Cancer Inst 99:1544-1550

28. Benedetti S, Bruzzone MG, Pollo B, DiMeco F, Magrassi L, Pirola B, Cirenei N, Colombo MP, Finocchiaro G (1999) Eradication of rat malignant gliomas by retroviral-mediated, in vivo delivery of the interleukin 4 gene. Cancer Res 59:645-652

29. Okada H, Villa L, Attanucci J, Erff M, Fellows WK, Lotze MT, Pollack IF, Chambers WH (2001) Cytokine gene therapy of gliomas: effective induction of therapeutic immunity to intracranial tumors by peripheral immunization with interleukin-4 transduced glioma cells. Gene Ther 8:1157-1166

30. Schiltz PM, Lee GJ, Hoa N, Wepsic HT, Dillman RO, Jadus MR (2007) Human tumor cells are susceptible to cytolysis by allogeneic and xenogeneic cells via distinct pathways. Cancer Biother Radiopharm 22:672-683 
31. Machulla HKG, Steinborn F, Schaaf A, Heidecke V, Rainov NG (2001) Brain glioma and human leukocyte antigens (HLA) - is there an association. J Neuro Oncol 52:253-261

32. Tang J, Shao W, Dorak MT, Li Y, Miike R, Lobashevsky E, Wiencke JK, Wrensch M, Kaslow RA, Cobbs CS (2005) Positive and negative associations of human leukocyte antigen variants with the onset and prognosis of adult glioblastoma multiforme. Cancer Epidemiol Biomark Prev 14:2040-2044

33. Tsurushima H, Liu SQ, Tsuboi K, Tsuboi K, Yoshii Y, Nose T, Ohno T (1996) Induction of human autologous cytotoxic $T$ lymphocytes against minced tissues of glioblastoma multiforme. J Neurosurg 84:258-263

34. Holladay FP, Heitz-Turner T, Bayer WL, Wood GW (1996) Autologous tumor cell vaccination combined with adoptive cellular immunotherapy in patients with grade III/IV astrocytoma. J Neuro Oncol 27:179-186

35. Plautz GE, Miller DW, Barnet GH, Glen H, Stevens J, Maffett S, Kim J, Cohen PA, Shu S (2000) T Cell adoptive immunotherapy of newly diagnosed gliomas. Clin Cancer Res 6:2209-2218

36. Hayes RL (1992) The cellular immunotherapy of primary brain tumors. Rev Neurol (Paris). 148:454-466

37. Quattrocchi KB, Miller CH, Cush S, Bernard SA, Dull ST, Smith M, Gudeman S, Varia MA (1999) Pilot study of local autologous tumor infiltrating lymphocytes for the treatment of recurrent malignant gliomas. J Neuro-Oncol 45:141-157

38. Kruse CA, Cepeda L, Owens B, Johnson SD, Stears J, Lillehei KO (1997) Treatment of recurrent glioma with intracavity alloreactive cytotoxic $\mathrm{T}$ lymphocytes and interleukin-2. Cancer Immunol Immunother 45:77-87

39. Kruse CA, Rubinstein D (2001) In: Liau LM, Becker DP, Cloughesy TF, Bigner DD (eds) Cytotoxic T-lymphocytes reactive to patient major histocompatibility complex proteins for therapy of brain tumors. Brain Tumor Immunotherapy. Humana Press, Totowa, NJ, pp 149-170

40. Huang Y, Hayes RL, Wertheim S, Arbit E, Scheff R (2001) Treatment of refractory recurrent malignant glioma with adoptive cellular immunotherapy: a case report. Crit Rev Onco-Hematol 39:17-23

41. Parney IF, Hao C, Petruk KC (2000) Glioma immunology and immunotherapy. Neurosurgery 46:778-786

42. Dranoff G, Jaffee E, Lazenby A, Golumbek P, Levitsky H, Brose K, Jackson V, Hamada H, Pardoll D, Mulligan RC (1993) Vaccination with irradiated tumor cells engineered to secrete murine granulocyte-macrophage colony stimulating factor stimulates potent, specific, and long lasting anti-tumor immunity. Proc Natl Acad Sci (USA) 90:3539-3543

43. Rutkowski S, De Vleeschouwer S, Kaempgen E (2004) Surgery and adjuvant dendritic cell-based tumour vaccination for patients with relapsed malignant glioma, a feasibility study. Br J Cancer 91:1656-1662

44. Liau LM, Prins RM, Kiertscher SM, Odesa SK, Kremen TJ, Giovannone AJ, Lin JW, Chute DJ, Mischel PS, Cloughesy TF, Roth MD (2005) Dendritic cell vaccination in glioblastoma patients induces systemic and intracranial $\mathrm{T}$-cell responses modulated by the local central nervous system tumor microenvironment. Clin Cancer Res 11:5515-5525

45. Wheeler CJ, Black KL, Liu G, Mazer M, Zhang XX, Pepkowitz S, Goldfinger D, Ng H, Irvin D, Yu JS (2008) Vaccination elicits correlated immune and clinical responses in glioblastoma multiforme patients. Cancer Res 68:5955-5964

46. Liu G, Akasaki Y, Khong HT, Wheeler CJ, Das A, Black KL, Yu JS (2005) Cytotoxic T cell targeting of Trp-2 sensitizes human human malignant glioma to chemotherapy. Oncogene 24:5226-5234

47. Hsu W, Lesniak MS, Tyler B, Brem H (2005) Local delivery of interleukin-2 and adriamycin is synergistic in the treatemnet of experimental malignant glioma. J Neuro-Oncol 74:135-140
48. Jeffes EWB, Zhang JG, Hoa N, Pektar A, Delgado C, Chong S, Obenaus A, Sanchez R, Khalaghizadeh S, Khomenko T, Knight BA, Alipanah R, Nguyen TV, Shah C, Vohra S, Zhuang JL, Liu J, Wepsic HT, Jadus MR (2005) Anti-angiogenic drugs synergize with a membrane macrophage colony stimulating factor based tumor vaccine to therapeutically treat rats with an established intracranial malignant glioma. J Immunol 174:2533-2543

49. Dudley ME, Wunderlich JR, Robbins PF, Yang JC, Hwu P, Schwartzentruber DJ, Topalian SL, Sherry R, Restifo NP, Hubicki AM, Robinson MR, Raffeld M, Duray P, Seipp CA, RogersFreezer L, Morton KE, Mavroukakis SA, White DE, Rosenberg SA (2002) Cancer regression and autoimmunity in patients after clonal repopulation with antitumor lymphocytes. Science 298:850-854 2002

50. Gogas H, Ioannovich J, Dafni U, Stavropoulou-Giokas C, Frangia K, Tsoutsos D, Panagiotou P, Polyzos A, Papadopoulos O, Stratigos A, Markopoulos C, Bafaloukos D, Pectasides D, Fountzilas G, Kirkwood JM (2006) Prognostic significance of autoimmunity during treatment of melanoma with interferon. New Engl J Med 354:709-718

51. Phan GQ, Yang JC, Sherry RM, Hwu P, Topalian SL, Schwartzentruber DJ, Restifo NP, Haworth LR, Seipp CA, Freezer LJ, Morton KE, Mavroukakis SA, Duray PH, Steinberg SM, Allison JP, Davis TA, Rosenberg SA (2003) Cancer regression and autoimmunity induced by cytotoxic $\mathrm{T}$ lymphocyte-associated antigen 4 blockade in patients with metastatic melanoma. PNAS 100:6251-6259

52. Weiden PL, Fluornoy N, Thomas ED, Prentice R, Fever A, Buckern CD, Storb R (1979) Antileukemic effects of graft-versus-host disease in human recipients of allogeneic marrow grafts. New Engl J Med 300:1068-1073

53. Weiden PL, Sullivan KM, Fluornoy N, Storb R, Thomas ED, Seattle Marrow Transplant Team (1981) Antileukemic effect of chronic graft-versus-host disease. Contribution to improved survival after allogeneic marrow transplantation. New Engl J Med 304:1529-1533

54. Makinodan T, Chang MP, Kinohara N (1986) Influence of age on cellular differentiation: a T cell model. Exp Gerontol 21:241

55. Miller RA (1996) The aging immune system: primer and prospectus. Science 273:70-74

56. Gomez CR, Nomellini V, Faunce DE, Kovacs EJ (2008) Innate immunity and aging. Exp Gerontol 43:718-728

57. De Vleeschouwer S, Fieuws S, Rutkowski S, Van Calenbergh F, Van Loon J, Goffin J, Sciot R, Wilms G, Demaerel P, WarmuthMetz M, Soerensen N, Wolff JEA, Wagner S, Kaempgen E, Van Gool SW (2008) Postoperative adjuvant dendritic cell-based immunotherapy in patients with relapsed glioblastoma multiforme. Clin Cancer Res 14:3098-3104

58. De Vleeschouwer S, Van Calenbergh Demaerel P, Flamen P, Rutkowski S, Kaempgen E, Wolff JE, Plets C, Sciot R, Van Gool SW (2004) Transient local response and persistent tumor control in a child with recurrent malignant glioma: treatment with combination therapy including dendritic cell therapy. J Neurosurg (Pediatrics 5) 100:492-497

59. Jacobs JFM, Coulie PG, Figdor CG, Adema GJ, de Vries IJM, Hoogerbrugge PM (2009) Targets for active immunotherapy against pediatric solid tumors. Cancer Immunol Immunother 58:831-841

60. Forni G, Lollini PL, Musiani P, Colombo MP (2000) Immunoprevention of cancer: is the time ripe? Cancer Res 60:2571-2575

61. Pearce EL, Walsh MC, Cejas PJ, Harms GM, Shen H, Wang LS, Jones RG, Choi Y (2009) Enhancing CD8 T-cell memory by modulating fatty acid metabolism. Nature doi:10.1038/ nature 08097

62. el-Shami K, Tirosh B, Bar-Haim E, Carmon L, Vadai E, Fridkin M, Feldman M, Eisenbach L (1999) MHC class I-restricted 
epitope spreading in the context of tumor rejection following vaccination with a single immunodominant CTL epitope. Eur $\mathbf{J}$ Immunol 29:3295-3301

63. Heimberger AB, Hussain FS, Aldape K, Sawaya R, Archer G, Friedman H, Reardon D, Friedman A, Bigner DD, Sampson JH (2006) Tumor-specific peptide vaccination in newly-diagnosed patients with GBM. J Clin Oncol 24/18S Part I (\#2529)

64. Mennuni C, Ugel S, Mori F, Cipriani B, Iezzi M, Pannellini T, Lazzaro D, Ciliberto G, La Monica N, Zanovello P, Bronte V, Scarselli E (2008) Preventive vaccination with telomerase controls tumor growth in genetically engineered and carcinogeninduced mouse models of cancer. Cancer Res 68:9865-9874

65. Tirino V, Desiderio V, d'Aquino R, De Francesco F, Pirozzi G, Galderisi U, Cavaliere C, De Rosa A, Papaccio G (2008) Detection and characterization of CD133+ cancer stem cells in human solid tumors. PLoS One 3:e3469

66. Bao S, Wu Q, McLendon, Hao Y, Shi Q, Hjelmeland AB, Dewhirst MW, Bigner DD, Rich JN (2006) Glioma stem cells promote radioresistance by preferential activation of the DNA damage response. Nature 444:756-760

67. Liu G, Yuan X, Zeng Z, Tunici P, Ng H, Abdu IR, Irvin D, Black $\mathrm{KL}, \mathrm{Yu}$ JS (2006) Analysis of gene expression and chemoresistance of CD133+ cancer stem cells in glioblastoma. Mol Cancer 5:67-74

68. Rebetz J, Tian D, Persson A, Widegren B, Salford LG, Englund E, Gisselsson D, Fan X (2008) Glial progenitor-like phenotype in low-grade glioma and enhanced CD133-expression and neuronal lineage differentiation potential in high-grade glioma. PLoS ONE 3:e1936

69. Nakano I, Masterman-Smith M, Saigusa K, Paucer AA, Horvath S, Saigusa K, Paucar AA, Horvath S, Shoemaker L, Watanabe M, Negro A, Bajpai R, Howes A, Lelievre V, Waschek JA, Lazareff JA, Freije WA, Liau LM, Gilbertson RJ, Cloughesy TF, Geschwind DH, Nelson SF, Mischel PS, Terskikh AV, Kornblum HI (2008) Maternal embryonic leucine zipper kinase is a key regulator of the proliferation of malignant brain tumors, including brain tumor stem cells. J Neurosci Res 86:48-60

70. Sasada T, Zeng W, Su M, Kang YJ, Zhang Z, Brusic V, Reinherz EL (2008) Identification of HLA-A0201-restricted cytotoxic T lymphocyte (CTL) epitopes from a novel melanoma antigen maternal embryonic leucine zipper kinase (MELK). AACR Meeting (\#4631)

71. Jacobs JFM, Hoogerbrugge PM, van de Rakt MWMM, Aarntzen EHJG, Figdor CG, Adema GJ, de Vries IJM (2007) Phenotypic and functional characterization of mature dendritic cells from pediatric cancer patients. Pediatr Blood Cancer 49:924-927

72. Geiger JD, Hutchinson RJ, Hohenkirk LF, McKenna EA, Yanik GA, Levine JE, Chang AE, Braun TM, Mule JJ (2001) Vaccination of pediatric solid tumor patients with tumor lysate-pulsed dendritic cells can expand specific $\mathrm{T}$ cells and mediate tumor regression. Can Res 61:8513-8519 